ORIGINAL ARTICLE

\title{
Dynamics of antibiotic resistance genes and presence of putative pathogens during ambient temperature anaerobic digestion
}

\author{
J.A. Resende ${ }^{1,2}$, C.G. Diniz ${ }^{1}$, V.L. Silva ${ }^{1}$, M.H. Otenio ${ }^{3}$, A. Bonnafous ${ }^{2}$, P.B. Arcuri ${ }^{4}$ and J.-J. Godon ${ }^{2}$ \\ 1 Department of Parasitology, Microbiology and Immunology, Institute of Biological Sciences, Federal University of Juiz de Fora, Juiz de Fora, \\ Brazil \\ 2 INRA — Institute National Recherche Agronomique, Laboratoire de Biotechnologie de l'Environnement, Narbonne, France \\ 3 EMBRAPA Dairy Cattle_-Brazilian Agricultural Research Corporation, Juiz de Fora, Brazil \\ 4 EMBRAPA Brazilian Agricultural Research Corporation, Secretariat for International Relations, Headquarters, Brasilia, Brazil
}

\section{Keywords}

antibiotics resistance gene abundance, bacterial pathogens, biofertilizer dairy cattle manure, biogas, seasonal variations.

\section{Correspondence}

Marcelo Henrique Otenio, EMBRAPA Dairy Cattle, Brazilian Agricultural Research Corporation, 36038-330, Juiz de Fora, MG, Brazil.

E-mail: marcelo.otenio@embrapa.br

2014/1244: received 17 June 2014, revised 9 September 2014 and accepted 19 September 2014

doi:10.1111/jam.12653

\begin{abstract}
Aims: This study was focused on evaluating the persistency of antimicrobial resistance (AR) genes and putative pathogenic bacteria in an anaerobic digesters operating at mesophilic ambient temperature, in two different year seasons: summer and winter.

Methods and Results: Abundance and dynamic of AR genes encoding resistance to macrolides (ermB), aminoglycosides (aphA2) and beta-lactams $\left(b l a_{\mathrm{TEM}-1}\right)$ and persistency of potentially pathogenic bacteria in pilot-scale anaerobic digesters were investigated. AR genes were determined in the influent and effluent in both conditions. Overall, after 60 days, reduction was observed for all evaluated genes. However, during the summer, anaerobic digestion was more related to the gene reduction as compared to winter. Persistency of potentially pathogenic bacteria was also evaluated by metagenomic analyses compared to an in-house created database. Clostridium, Acinetobacter and Stenotrophomonas were the most identified.

Conclusions: Overall, considering the mesophilic ambient temperature during anaerobic digestion (summer and winter), a decrease in pathogenic bacteria detection through metagenomic analysis and AR genes is reported. Although the mesophilic anaerobic digestion has been efficient, the results may suggest medically important bacteria and AR genes persistency during the process.

Significance and Impact of the Study: This is the first report to show AR gene dynamics and persistency of potentially pathogenic bacteria through metagenomic approach in cattle manure ambient temperature anaerobic digestion.
\end{abstract}

\section{Introduction}

Untreated animal manure may comprise several diseasecausing micro-organisms and constitutes reservoir of antimicrobial resistance (AR) genes. Large amounts of antibiotic compounds are applied in animal farming for growth promotion, prophylaxis and, at therapeutic levels, for treatment of infections. This practice may contribute to the increased percentages of resistant bacteria worldwide isolated from farm animals (Sahlström et al. 2004).
In addition, the occurrence of enteropathogenic bacteria, such as enterococci, and Gram-negative rods (Escherichia coli and Salmonella spp.) has already been reported in cattle manure, and it is accepted that these animals play an important role in the spread of these potentially pathogenic bacteria to the surrounding environment (Sahlström et al. 2004; Venglovsky et al. 2009).

In an attempt to avoid the manure direct discharge into soil and aquatic ecosystems, anaerobic digestion technology is pointed out as an alternative to the sanitary 
problems associated with the livestock areas (Holm-Nielsen et al. 2009). This technology is widely used in several countries resulting in biogas, and residues rich in nutrients, which can be used as fertilizers (Abubaker et al. 2012). Moreover, without any risk assessment, according to the literature, these fertilizers would be associated with the soil contamination by multiresistant potentially pathogenic bacteria (Eikmeyer et al. 2013). In this regard, temperature is pointed out as the dominant inactivating factor, as observed during mesophilic or thermophilic anaerobic digestion (Beneragama et al. 2013). Horizontal transfer of antibiotic resistance determinants is considered an important safety issue, and the input of resistance genes with effluent digesters could well contribute to the resistance problem in human antibiotic therapy (Heuer et al. 2011; Pruden et al. 2013).

Although the Brazilian climatic conditions are in the mesophilic range and most of the anaerobic digesters are operated at ambient temperature followed by land application (Kunz et al. 2009), there are no literature data available regarding risk assessments concerning the stability of potentially pathogenic bacteria or even inactivation of AR genes.

A recent report describes the isolation of multidrugresistant bacteria from anaerobic digestion effluents and influent in ambient temperature pilot-scale digesters (Resende et al. 2014). From that study, samples were collected equally during two different periods (summer and winter) to provide new insights into further investigations related to the sanitary risks of the process concerning human and environmental health. At this point, this study provides original information on the persistency of the AR genes (macrolides, aminoglycosides and beta-lactams) and 16S rRNA gene sequencing for identification of potentially pathogenic bacteria. The AR genes evaluated in this study are representative of major genetic markers associated with the antimicrobial resistance considering drugs commonly used in dairy cattle management in Brazil, also relevant considering human medicine (Nero et al. 2007; Kemper 2008 Fonseca et al. 2009; Pribul et al. 2011).

\section{Material and methods}

\section{Pilot-scale reactor conditions}

Two reactors operating ambient temperatures in different seasons, with a 60-day retention time and 60-1 working volume, were used. Fresh dairy cattle manure was collected weekly, in the same location, at the experimental Embrapa dairy cattle field located in Coronel Pacheco city, Minas Gerais state, Brazil.

The samples were transported immediately to the laboratory within $30 \mathrm{~min}$, under refrigeration in ice box, and stored at $4^{\circ} \mathrm{C}$, up to $96 \mathrm{~h}$, according to the established procedures (Wang et al. 2012). As long as the dairy cows have been treated with beta-lactam (penicillin) in clinical or subclinical mastitis infections in the experimental Embrapa dairy cattle field, at the time of sample collection, the animals did not receive any antimicrobial drugs in the past 30 days.

Physical-chemical parameters were estimated as per standard methods (APHA 2005). Before being used as substrate in the pilot-scale digesters, the manure was diluted with cattle wastewater to a total solids (TS) concentration of $4-5 \%$, and after for daily addition at an amount of 21 .

The samples were collected equally from during two different periods: between January to March (2012) (summer) and June to July (2012) (winter). Ambient temperature was in the mesophilic range, between 14 and $25^{\circ} \mathrm{C}$ (average $19.5^{\circ} \mathrm{C}$ ) in winter and $24-34^{\circ} \mathrm{C}$ (average $29 \cdot 5^{\circ} \mathrm{C}$ ) in summer.

The $\mathrm{pH}$ value of the cattle manure (influent) was between 6.55 and 6.86 , and the loading rates were around $13.3 \mathrm{~g} \mathrm{ml}^{-1}$ of volatile solids (VS) in the summer and $12.4 \mathrm{~g} \mathrm{ml}^{-1}$ of $\mathrm{VS}$ in the winter months. In all digesters, the percentage reduction in total solids of fermenting cattle manure was about $65 \%$ and VS was $68 \%$. The average daily biogas produced in summer and winter months was 18.7 and 161 per day, respectively. There was no significant difference in the methane content of the biogas produced in summer (59.2\%) and winter (53.7\%) months (ANOVA, $P=0 \cdot 73$ ). There was no significant difference in the average methane yield between the reactors operated in the summer $\left(0.11-1.18 \mathrm{l} . \mathrm{g} \mathrm{VS}_{\text {added }}{ }^{-1}\right)$ and winter $\left(0 \cdot 25-0 \cdot 77\right.$ l.g $\left.\mathrm{VS}_{\text {added }}{ }^{-1}\right)$ months (ANOVA, $P=0 \cdot 60$ ).

\section{DNA extraction}

Samples were identified according to season, day of collection and source (between the two digesters): samples collected during the summer and winter were denoted with the letters $S$ (Summer) and $W$ (Winter), respectively; the numbers (0-60) were added according to the sampling days during anaerobic digestion after initial load. The letters ( $a$ and b) corresponded to each of the digesters where the fermentation was carried out. In total, 58 samples from the digesters were collected at different time points, referred as 2 anaerobic digesters influent (S0 and W0) and 56 anaerobic digesters effluent samples starting from the 4th day after initial load (S4 to S60 and W4 to W60).

Influent (S0 and W0) and effluent (S4 to S60 and W4 to W60) samples $(20 \mathrm{ml})$ were collected using sterile bottles. Upon receipt, aliquots of $10-15 \mathrm{ml}$ of each sample were ultrasonic-treated by sonication on ice for $1 \mathrm{~min}$ 
(cycle, 1.0; amplitude, 100\%) with a UP100H Sonicator (Hielscher Ultrasound Technology, Teltow, Germany). Further, 5-ml aliquots of each sample were centrifuged $15 \mathrm{~min}$ at $14000 \mathrm{~g}$, at $4^{\circ} \mathrm{C}$, and the pellet was kept for genomic DNA extraction using the QIAamp DNA Stool Mini Kit, according to the manufacturer's instruction (Qiagen, Heidelberg, Germany). The DNA concentrations were quantified using a NanoDrop ND-1000 (NanoDrop Technologies, Wilmington, DE) and stored at $-20^{\circ} \mathrm{C}$ until use.

\section{Quantitative PCR (qPCR)}

Quantitative PCRs were used to quantify the abundance of three selected $\mathrm{AR}$ genes $\left(\operatorname{erm} \mathrm{B}, a p h \mathrm{~A} 2\right.$ and $b l a_{\mathrm{TEM}-1}$, associated with macrolide, aminoglycoside and beta-lactams resistance, respectively), in the effluent or influent DNA samples (Table 1). Plasmids containing the target AR genes were used as standard DNA templates for each of the qPCRs. The plasmids were decimally diluted to range from $10^{9}$ to 100 copy numbers. All of the qPCR amplifications and quantifications were performed using a CFX96 Real Time Detection System (Bio-Rad Laboratories, Inc., Hercules, CA). Reaction mixtures $(25 \mu \mathrm{l})$ contained $12.5 \mu \mathrm{l}$ Sso-Advanced SYBR Green Supermix (Bio-Rad Laboratories, Inc.), $1 \mu \mathrm{l}$ forward and reverse primers $\left(0.2 \mathrm{mmol} \mathrm{l}^{-1}\right), 5 \mu \mathrm{l}$ of template DNA with two appropriate dilutions $(0 \cdot 1$ and $1 \mathrm{ng} \mu \mathrm{l}^{-1}$ ) and $5.5 \mu \mathrm{l}$ ultra-pure PCR grade water. The following thermal program was used: initial incubation of $2 \mathrm{~min}$ at $95^{\circ} \mathrm{C}$ and 40 cycles of denaturation at $95^{\circ} \mathrm{C}$ for $15 \mathrm{~s}$, annealing at the given temperatures (Table 1) for $1 \mathrm{~min}$ and a final melt curve stage with temperature ramping from 65 to $95^{\circ} \mathrm{C}$. Melting curve analysis of the PCR products was conducted following each assay to confirm that the fluorescence signal originated from specific PCR products. Then, results were compared with a standard curve to obtain the number of target copies in the sample. PCR efficiency of each gene ranged from 94.7 to $102.3 \%$ with $\mathrm{R}^{2}$ value more than 0.99 for the calibration curves.

Quantification of the bacterial 16S rRNA gene was also performed using the universal bacterial primer set W208 $\left(250 \mathrm{nmol} \mathrm{l}^{-1}\right)$, W209 (250 $\mathrm{nmol} \mathrm{l}^{-1}$ ) and probe W210 $\left(50 \mathrm{nmol} \mathrm{l}^{-1}\right.$ ) as previously described (Yu et al. 2005). For total bacteria, the standard curves were generated by amplification of serial 10-fold dilutions of a reference clone (Snell-Castro et al. 2005).

Baseline and threshold calculations were performed with the $\mathrm{CFX}^{\circledR}$ Manager software 3.0 (Bio-Rad Laboratories, Inc). The presence of PCR inhibitors was checked by serially diluting select samples and comparing PCR efficiencies with standards. All qPCRs were done in triplicate for both the standards and the microbial community DNA samples. The total bacteria abundance, ermB, aphA2 and $b l a_{\mathrm{TEM}-1}$ were finally expressed as the number of target copies per gram of effluent or influent. The relative abundance was then calculated by dividing the absolute abundance of each AR gene by total bacteria absolute abundance in each sample.

\section{Sequencing of $16 \mathrm{~S}$ rRNA gene and pathogen identification}

DNA extracts from the final samples (S60a, S60b, W60a and W60b) were selected for high-throughput sequencing analysis. A mixture of amplicons generated from F515 and R928 primers (Table 1) were sequenced on a 454 GS-FLX Titanium sequencer (Roche Life Sciences, Branford, CT, USA) at the Molecular Research Laboratory (Shallowater, TX). After sequencing, all failed sequence reads, low-quality sequence ends and tags were removed. Mothur software package (Schloss et al. 2009) was used to remove the redundancy of the tag sequences and select

Table 1 Sequences and target positions of primers used in this study

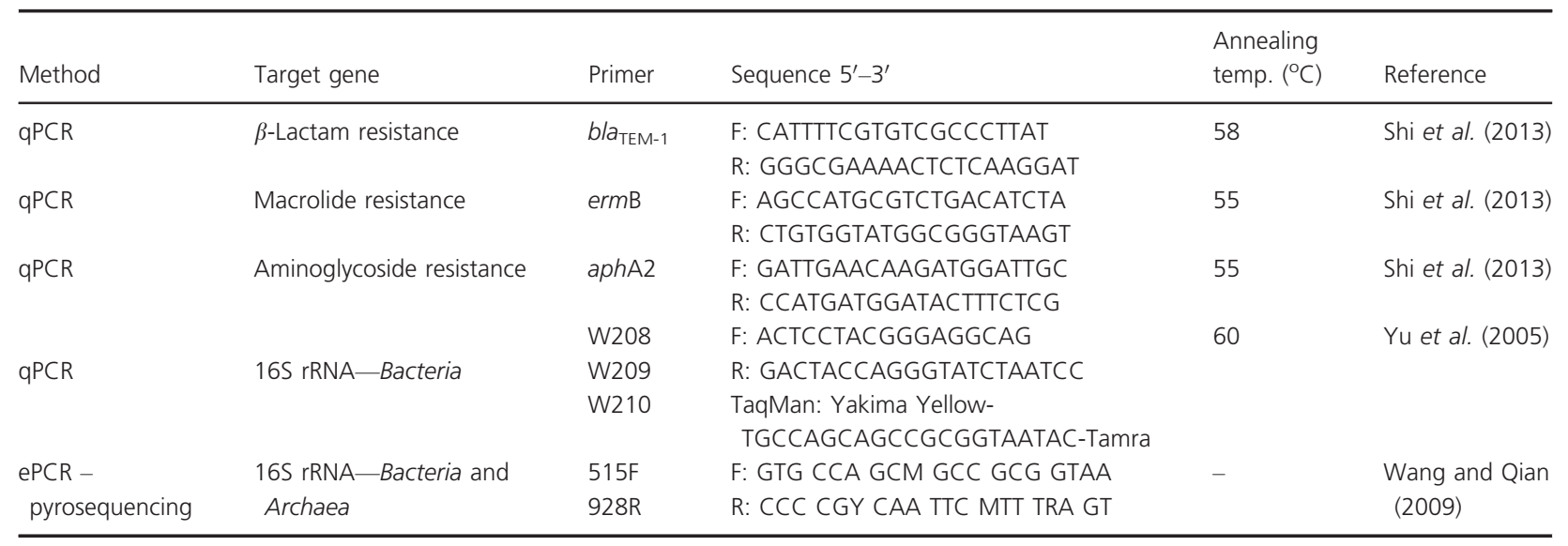


unique tag sequences (each unique tag therefore represented different numbers of tag sequences). Briefly, flowgrams were quality-controlled and de-noised with the trim.flows, shhh.flows, trim.seqs and unique.seqs commands; aligned against the SILVA reference database (Pruesse et al. 2007) using align.seqs; and chimerachecked with the chimera.uchime command. Using the classify.seqs command, final sequence data set was classified considering the SILVA taxonomy distributed with Mothur. The number of sequences obtained was 17531 from all samples. Operational taxonomic units (OTUs) were defined as group of sequences with a $P$-distance of $3 \%$ (or $97 \%$ similarity) succeeding construction of a distance matrix by commands dist.seqs and cluster.

OTUs were then taxonomically classified using BLASTn against our in-house created database of pathogenic 16S rRNA sequences. The $3016 \mathrm{~S}$ rRNA gene sequences analysed in this study included the sequences from known pathogenic bacteria. The $16 \mathrm{~S}$ rRNA gene sequences corresponding to each species were retrieved from GenBank database. The most representative 16S rRNA gene was chosen for analysis according to the following standards: (i) strains with good phenotypic characterization; (ii) strains isolated as a source of contamination or infection in humans; and (iii) sequences with fewer undetermined bases.

For final classification, a bacterium species is defined as 'confidently identified by $16 \mathrm{~S}$ rRNA gene sequencing' if there is $>95 \%$ identify over an alignment and at least $249 \mathrm{bp}$ assigned to the respective $16 \mathrm{~S}$ rRNA gene sequence of the medically important bacteria species.

\section{Nucleotide sequence accession numbers}

Sequence data associated with this study are deposited in GenBank's Short Read Archive (SRA) under the accession number SRP041213.

\section{Data analysis}

To report an average performance of anaerobic digestion processes in both seasons, multiple sampling events were treated as replicates. Averages and standard errors of all data were determined. The treatment data of erm $\mathrm{B}$, $a p h \mathrm{~A} 2$ and $b a_{\mathrm{TEM}-1}$ gene abundance were first $\log _{10^{-}}$ transformed to improve normality and then analysed by one-way analysis of variance (ANOVA) procedure for independent samples to test for statistically significant differences. A $P$-value of $<0.05$ was considered to indicate significance. Co-occurrence of different AR genes was examined based on the association between the relative abundance of two gene classes by Pearson productmoment correlation coefficient.

\section{Results}

The dynamics of AR genes in influent and effluent samples from duplicate anaerobic digesters were investigated over a 60 days of fermentation in two different seasons (summer and winter), and in the final samples, pathogenic bacteria were searched using $16 \mathrm{~S}$ rRNA sequencing data. For each samples during anaerobic process, the number of ermB, aphA2 and $b l a_{\mathrm{TEM}-1}$ gene copies per gram of influent or effluent was determined from the average of the two replicas operated during each season. The antibiotics removal efficiency was assessed by considering influent (day 0) and effluent (day 60) values. When all AR genes were normalized to 16S rRNA genes, relative abundance, the reductions in the different anaerobic processes on AR genes, maintained a remarkably similar trend.

\section{Dynamics of the total bacteria}

To compare absolute reductions of AR genes, gene quantities were compared with the absolute abundance of total bacterial 16S rRNA gene. All results were similar from each replica, in both digesters operated in the summer (ANOVA, $P=0.999$ ) as in the two operated in winter (ANOVA, $P=0 \cdot 809$ ). For each samples during anaerobic process, the concentration of bacterial copies per gram of effluent or influent was carried out from the average of the two replicas operated during each season. The mean numbers of $16 \mathrm{~S}$ rRNA gene copies were $2.8 \times 10^{9}$ and $6.4 \times 10^{9}$ in the summer and winter samples, respectively. No significant differences in abundances were found (ANOVA, $P=0 \cdot 700$ ) in different seasons, suggesting that, independent of the season, a similar dynamic and abundance were obtained during the 60 days of fermentation.

\section{Dynamic of macrolides resistance genes}

The presence of erm $\mathrm{B}$ genes throughout the anaerobic digestion process in different seasons was evaluated, and the patterns observed in different time points are shown in Fig. 1. The influent contained substantial quantities of ermB genes, concentration of approx. $10^{6}$ gene copies per gram, and they were similar in both seasons. The dynamics of ermB in both seasons exhibited a similar pattern, decreasing in a time-dependent manner. During the summer and winter months, the abundance of erm B was nearly 1-log-cycle lower in the effluent after 60 days of fermentation than the influent (samples of the first day). $93.9 \%$ of ermB were reduced in the anaerobic process in the summer and $84.0 \%$ in the winter months. 

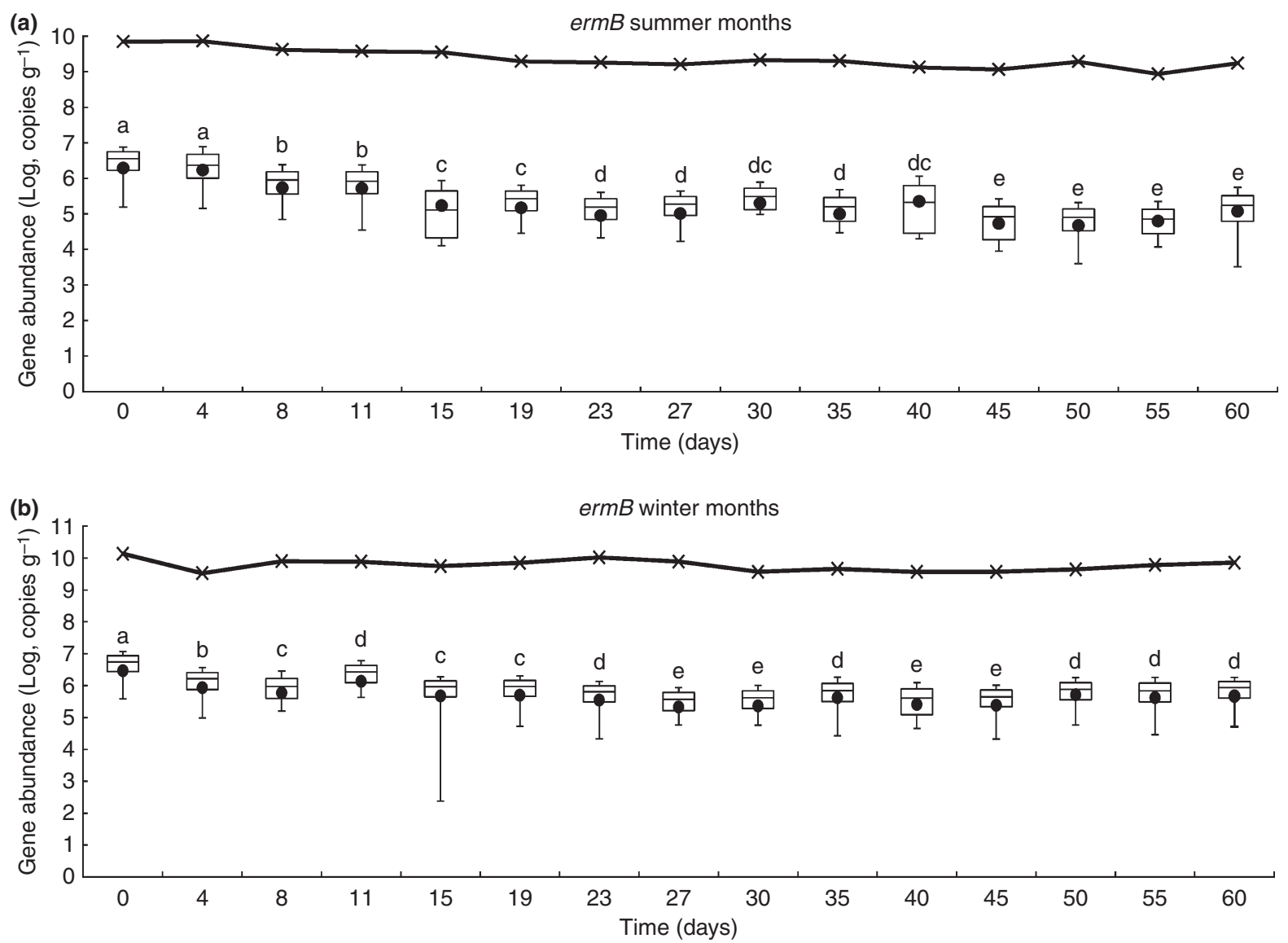

Figure 1 Box and whisker plot of absolute abundance of ermB gene during the anaerobic digestion in the summer (a) and winter months (b). All ermB data are expressed as $\log _{10}$ copies per gram of influent or effluents samples. Errors bars indicate maximum and minimum values; horizontal lines indicate median values; and boxes indicate values between the 25th and 75th percentiles. Different letters designate statistical significance $(P<0.05)$. Values of symbols $(\bullet)$ and $(x)$ indicate ermB mean and operation time variation of 165 rRNA mean, respectively.

\section{Dynamic of aminoglycosides resistance genes}

The quantities of aphA2 genes in different samples of anaerobic digestions process with varied temperatures are compared in Fig. 2. The abundance of aph $\mathrm{A} 2$ genes in influents not varied between the summer and winter anaerobic systems (nearly $10^{4}$ gene copies). In winter months, the absolute abundance of aphA2 did not decrease significantly over the first 30 days of fermentation, and the decrease thereafter was smaller than observed for summer months. In the last samples (day 60), the concentrations were nearly $10^{2}$ and $10^{3}$ gene copies in the summer and winter, respectively. In the summer months, the removal rate was nearly $2 \cdot 2-\log$-cycle, whereas in the winter months, it was 1-log-cycle reduction.

\section{Dynamics of beta-lactams resistance genes}

Quantitative changes of $b l a_{\mathrm{TEM}-1}$ in the different anaerobic reactors are shown in Fig. 3. In the initial samples, $b l a_{\mathrm{TEM}-1}$ was nearly $10^{7}$ copies per gram samples. In the summer conditions, the high quantities of $b l a_{\mathrm{TEM}-1}$ persisted well during 15 days and after that reduced in response to anaerobic digestion process, resulting in nearly $10^{4}$ gene copies on day $60(2 \cdot 2-\log$-cycle reduction). In the winter months, there was also a slight decrease in the quantification of $b l a_{\mathrm{TEM}-1}$, resulting in nearly $10^{4}$ gene copies on day $60(0 \cdot 84$-log-cycle reduction).

\section{Correlations and comparison between gene copy concentrations}

In the initial samples, compared with the other genes evaluated, aphA2 genes were detected at the lowest abundance and $b l a_{\mathrm{TEM}-1}$ was the most abundant. Comparisons between winter and summer effluent samples showed that all results of quantification indicated an interaction between seasons' patterns affected the resistance determinant. 

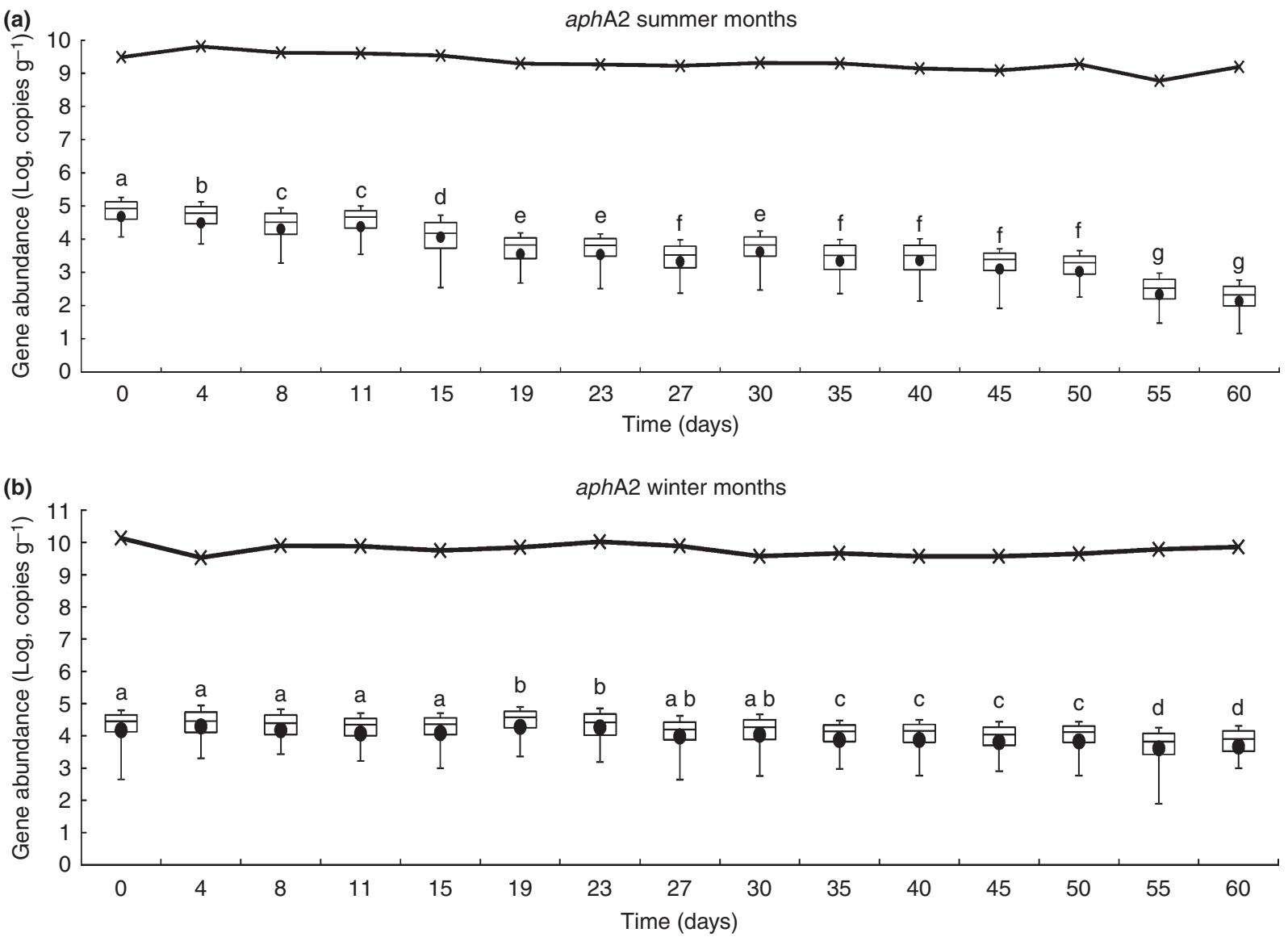

Figure 2 Box and whisker plot of absolute abundance of aphA2 gene during the anaerobic digestion in the summer (a) and winter months (b). All aphA2 data are expressed as $\log _{10}$ copies per gram of influent or effluents samples. Errors bars indicate maximum and minimum values; horizontal lines indicate median values; and boxes indicate values between the 25th and 75th percentiles. Different letters designate statistical significance $(P<0.05)$. Values of symbols $(\bullet)$ and $(x)$ indicate aphA2 mean and operation time variation of 165 rRNA mean, respectively.

Correlations with the different AR genes were examined by calculating the Pearson correlation coefficient between the erm $\mathrm{B}, a p h \mathrm{~A} 2$ and $b l a_{\mathrm{TEM}-1}$ genes among all the influent and effluent samples evaluated (Table 2). The number of copies of all resistance genes was normalized to the basal level of $16 \mathrm{~S}$ rRNA genes to minimize the variance caused by differences in background bacterial abundances. Positive correlation coefficient between AR genes tends to changes in abundance in the same direction, while a negative correlation coefficient indicates otherwise (Wang et al. 2012).

Among the relative abundance of all AR genes evaluated, all were positively correlated in both conditions. The strongest correlations observed were between aph $\mathrm{A} 2$ and $b l a_{\text {TEM-1 }}$ in summer months. Only a weak positive correlation between aph $\mathrm{A} 2$ and erm $\mathrm{B}$ in the winter month process was also observed (0.495).

\section{Putative pathogens sequences}

To identify possible pathogens sequences within each library in both seasonal conditions, BLAST analyses against our in-house created database of 30 pathogenic $16 \mathrm{~S}$ rRNA sequences were accomplished. With the purpose of comparing the microbial structure among these samples, operational taxonomic units (OTUs) were determined for each sample at distance levels of $3 \%$. A total of 17531 sequences were classified into 1710 OTUs (1676 OTUs for the domain Bacteria; 34 OTUs for the Archaea) based on BLASTn results.

The sequences that were within a $95 \%$ similarity of a list of 30 known pathogen sequences were counted as potential pathogens and are presented in Table 3. Microbial identification through $16 \mathrm{~S}$ rRNA genes showed persistence of these bacteria in final samples in both seasons. Among the total number of sequences obtained for the 
(a) bla $_{\text {TEM-1 }}$ summer months

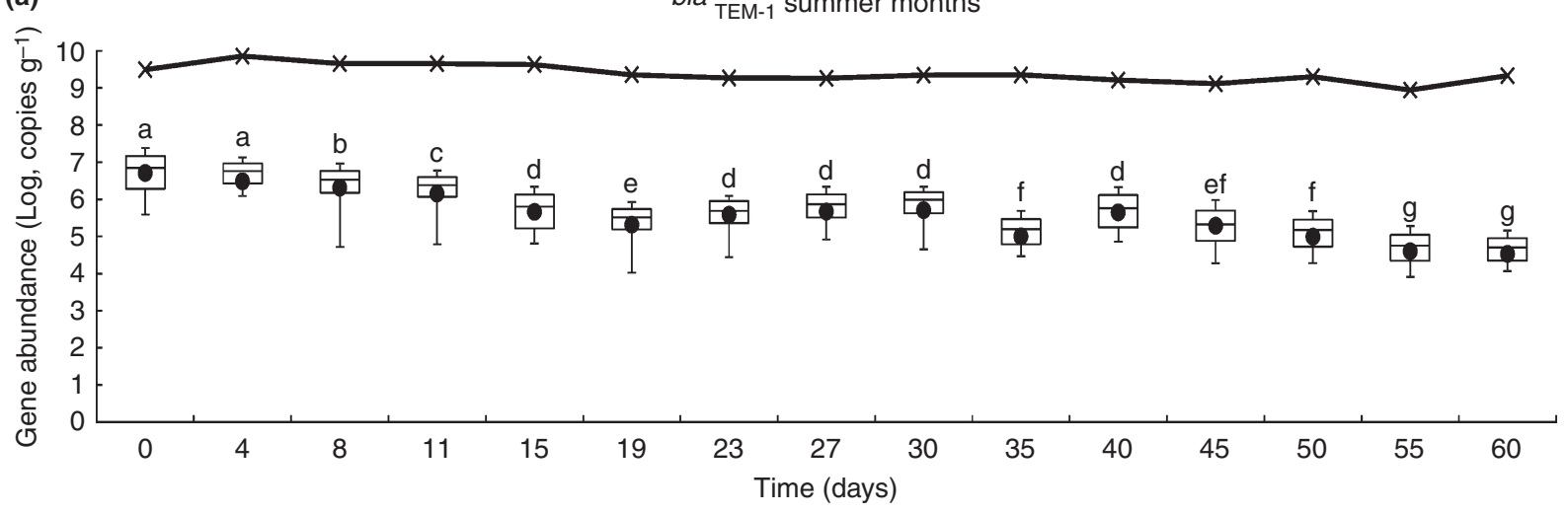

(b)

bla $_{\text {TEM-1 }}$ winter months

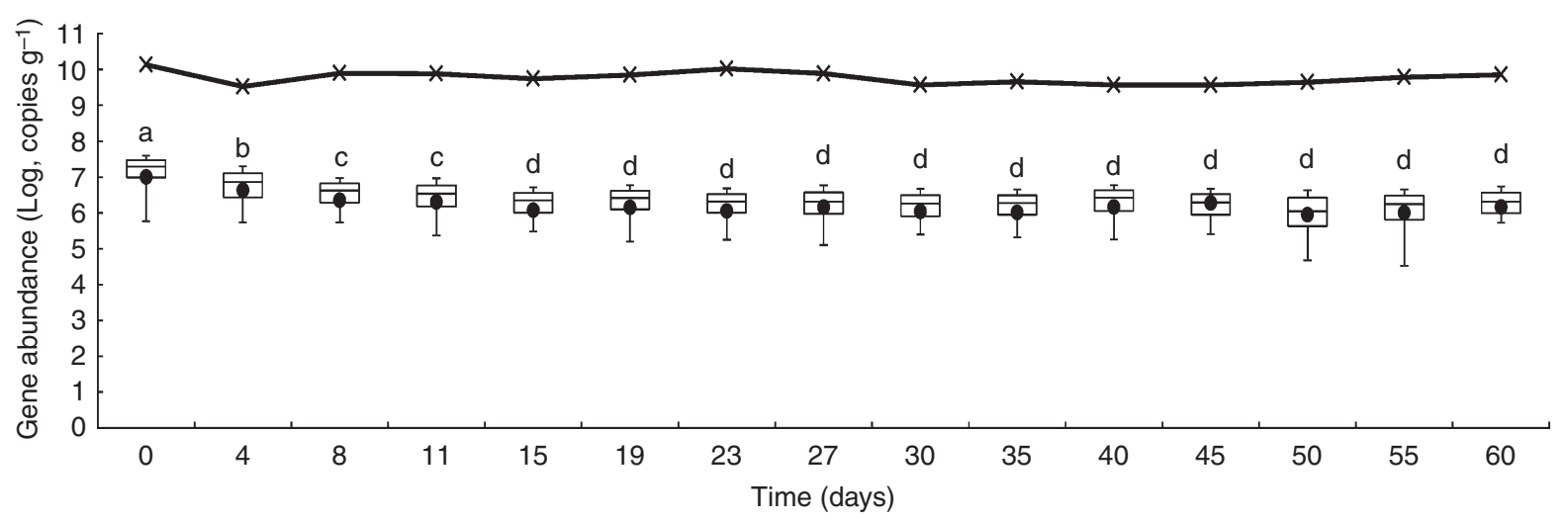

Figure 3 Box and whisker plot of absolute abundance of bla $\mathrm{TEM}_{\mathrm{TE}}$ gene during the anaerobic digestion in the summer (a) and winter months (b). All bla TEM-1 data are expressed as $\log _{10}$ copies per gram of influent or effluents samples. Errors bars indicate maximum and minimum values; horizontal lines indicate median values; and boxes indicate values between the 25 th and 75 th percentiles. Different letters designate statistical significance $(P<0.05)$. Values of symbols $(\bullet)$ and $(x)$ indicate bla TEM-1 mean and operation time variation of $16 \mathrm{~S}$ rRNA mean, respectively.

Table 2 Pearson correlation coefficient between relative abundance of different resistance (AR/16S-rRNA genes) in all anaerobic digestion samples

\begin{tabular}{llll}
\hline & ermB & aphA2 & bla TEM-1 \\
\hline ermB & 1 & $0.495^{*}$ & $0.803^{*}$ \\
aphA2 & $0.803 \dagger$ & 1 & $0.720 *$ \\
blaTEM-1 & $0.812 \dagger$ & $0.960 \dagger$ & 1 \\
\hline
\end{tabular}

*The top right triangular matrix is based on the relative abundance of winter months' anaerobic digestion samples.

$\uparrow$ The bottom left triangular matrix is based on the relative abundance of summer months' anaerobic digestion samples.

different reactors, only about $0 \cdot 73-1 \cdot 38 \%$ in the summer and $2 \cdot 59-2 \cdot 60 \%$ in the winter samples represent sequence of putative pathogens.

Of the 30 pathogen sequence considered, only 16 different pathogens were identified within the databases by sequence similarity. Gram-positive, such as Clostridium and Bacillus, and Gram-negative, such as Acinetobacter baumannii and Stenotrophomonas, were the most identified bacteria in the final samples.

All results were similar from each replica, in both digesters operated in the summer (ANOVA, $P=0 \cdot 191$ ) as in the two operated in winter (ANOVA, $P=0.993$ ). No significant differences in abundances of pathogens sequences were found between summer and winter samples (ANOVA, $P=0.463$ ), suggesting that independent of the season, all reactors obtained a similar abundance of pathogens after 60 days of fermentation.

\section{Discussion}

According to the literature, it is important to highlight the sanitary safety during the anaerobic digestion, especially if its final products, that is anaerobic digestion effluent (biofertilizer), are intended for environmental use (Walsh et al. 2012). As cattle manure is considered a reservoir for potentially pathogenic and antimicrobial resistant bacteria, a safe load reduction for these micro-organisms or its 
Table 3 Percentage of sequences belonging to selected pathogenic bacterial 16S rRNA evaluated during the anaerobic digestion in final samples of the summer and winter months anaerobic digestion

\begin{tabular}{|c|c|c|c|c|}
\hline \multirow[b]{2}{*}{ Species (NCBI sequence identification) } & \multicolumn{4}{|c|}{$\%$ of total } \\
\hline & S60a & S60b & W60a & W60b \\
\hline Acinetobacter baumannii ATCC 17978 (NC_009085) & 0.19 & 0.02 & 1.72 & 0.61 \\
\hline Burkholderia cepacia (GQ359110) & ND & ND & ND & ND \\
\hline Bacillus anthracis str. H9401 (NC_017729) & 0.15 & 0.02 & 0.22 & 0.41 \\
\hline Bacteroides fragilis 638R (FQ312004) & ND & ND & 0.02 & ND \\
\hline Campylobacter jejuni subsp. jejuni (CP001900) & ND & ND & ND & ND \\
\hline Citrobacter freundii ATCC 8090 (ANAV01000042) & ND & ND & ND & ND \\
\hline Clostridium botulinum NCTC 2916 (NZ_ABDO02000001) & ND & ND & 0.02 & ND \\
\hline Clostridium difficile CD196 (NC_013315) & 0.17 & 0.30 & 0.13 & 0.64 \\
\hline Clostridium perfringens (NZ_ABDY01000045) & 0.04 & 0.02 & 0.02 & 0.03 \\
\hline Clostridium tetani E88 (NC_004557) & ND & ND & ND & ND \\
\hline Corynebacterium diphtheriae HC01 (NC_016786) & 0.04 & 0.07 & 0.09 & 0.47 \\
\hline Enterococcus faecalis ATCC 4200 (NZ_GG670380) & ND & 0.07 & 0.07 & 0.12 \\
\hline Enterococcus faecium (AY172570) & ND & 0.07 & 0.07 & 0.12 \\
\hline Escherichia coli ATCC 8739 (NC_010468) & ND & ND & ND & ND \\
\hline Fusobacterium nucleatum subsp. nucleatum ATCC 25586 (NC_003454) & ND & ND & ND & ND \\
\hline Haemophilus influenzae 86-028NP (NC_007146.2) & ND & ND & ND & ND \\
\hline Klebsiella pneumoniae pneumoniae HS11286 (CP003200) & ND & 0.05 & ND & ND \\
\hline Listeria monocytogenes (S55472.1) & ND & ND & ND & ND \\
\hline Mycobacterium tuberculosis F11 (NC_009565.1) & ND & ND & ND & ND \\
\hline Pseudomonas aeruginosa NCGM2.S1 (AP012280) & 0.04 & ND & ND & ND \\
\hline Neisseria meningitidis M01-240149 (СР002421) & ND & ND & ND & ND \\
\hline Salmonella enterica subsp. enterica serovar choleraesuis str. SC-B67 (NC_006905.1) & ND & 0.05 & ND & ND \\
\hline Staphylococcus aureus subsp. aureus (NZ_GG730226) & ND & ND & ND & ND \\
\hline Staphylococcus epidermidis RP62A (NC_002976) & ND & ND & ND & ND \\
\hline Stenotrophomonas maltophilia K279a (NC_010943) & $0 \cdot 10$ & 0.02 & 0.24 & 0.20 \\
\hline Streptococcus agalactiae GD201008-001 (CP003810) & ND & 0.23 & ND & ND \\
\hline Streptococcus pneumoniae ATCC 700669 (NC_011900) & ND & 0.23 & ND & ND \\
\hline Streptococcus pyogenes MGAS5005 (NC_007297) & ND & 0.23 & ND & ND \\
\hline Vibrio cholerae 01 biovar eltor str. N16961 (NC_002505) & ND & ND & ND & ND \\
\hline Yersinia enterocolitica subsp. enterocolitica (NC_008800) & ND & ND & ND & ND \\
\hline Total percentage & 0.73 & $1 \cdot 38$ & 2.59 & $2 \cdot 60$ \\
\hline Total sequence & 5183 & 4338 & 4594 & 3416 \\
\hline
\end{tabular}

ND, not detected.

transferable genes figures as one of the sanitary concerns regarding the technological use of anaerobic digestion (Sahlström et al. 2004; Eikmeyer et al. 2013).

With regard to the antimicrobial resistance phenomenon, there are several calls on the impacts of antimicrobial use in both human and veterinary medicine (Heuer et al. 2011). In an attempt to access such sanitary risks, genetic markers representative of those associated with antimicrobial resistance commonly used in both human and veterinary medicine were chosen (Nero et al. 2007; Fonseca et al. 2009; Pribul et al. 2011). The gene erm B is related to macrolides, such as erythromycin, clarithromycin and azithromycin, besides lincosamide and streptogramin resistance; aphA2 is related to the resistance against aminoglycosides such as amikacin, gentamicin, kanamycin, neomycin, streptomycin and tobramycin; and $B l a_{\mathrm{TEM}-1}$ is related to the resistance against penicillins such as benzylpenicillin and amoxicillin, and cephalosporins such as cephalothin, cefazolin and cefoxitin (Syrogiannopoulos et al. 2003; Ramirez and Tolmasky 2010; Salverda et al. 2010).

Thus, to contribute to the understanding on the persistence of AR genes and putative pathogenic bacteria in cattle manure anaerobic digestion operating at ambient temperature, this study investigated the influence of the seasonal patterns either in summer (average temperature $29.5^{\circ} \mathrm{C}$ ) or in winter (average temperature $19 \cdot 5^{\circ} \mathrm{C}$ ) and operation time (during 60 days of fermentation) on AR genes load, and in the final samples, pathogenic bacteria were searched using $16 \mathrm{~S}$ rRNA sequencing data.

Copies of 16S rRNA genes displayed a similar trend in both anaerobic processes (summer and winter) during the 60 days of fermentation. The mean concentrations of $16 \mathrm{~S}$ rRNA in both seasons were on the same order as 
values, and this result is in accordance with other studies which observed total bacterial load during anaerobic digestion (Alexander et al. 2011).

Analysis of the occurrence and abundance of AR genes showed that $b l a_{\mathrm{TEM}-1}, a p h \mathrm{~A} 2$ and ermB were prevalent in the influent and effluent samples of anaerobic digestion. Plasmid-mediated erm $\mathrm{B}$ genes generally confer resistance to macrolide, lincosamide and streptogramin and have been commonly detected in cattle environments (Chen et al. 2007; Negreanu et al. 2012). Previous studies also observed the occurrence of $b l a_{\mathrm{TEM}-1}$ and $a p h \mathrm{~A} 2$ in intestinal bacteria and in the environment (Shi et al. 2013). All these genes have been reported as highly transferable among both Gram-negative and Gram-positive bacteria (Roberts 2008; Lachmayr et al. 2009).

Comparatively, the genes showed different initial abundance, and $b l a_{\mathrm{TEM}-1}$ and $e r m \mathrm{~B}$ were in higher amounts in the influent. These observations support previous research showing that resistance to these antibiotics is widespread and highlight persistent offering selective pressure in these wastes, resulting in drug-resistant bacteria recover, even if during animal management, antibiotics had never been used (Alexander et al. 2008; Heuer et al. 2011; Munir and Xagoraraki 2011). The spread of genes encoding for antimicrobial resistance among ruminant microbiota and manure bacteria is potentially relevant. As an adaptive consequence, the genetic mobility of such genes warrants the bacteria survivor, playing a role as a long-term reservoir of antibiotic resistance determinants (Ghosh and LaPara 2007).

The results revealed that ambient temperature anaerobic process was effective in reducing the initial load of AR genes. More detailed analysis of the AR gene dynamics showed that the genes were reduced to lower amounts and declined over time in the digesters. Thus, the abundance and removal of AR genes varied along fermentation process probably by seasons and operation time patterns. Such differences could outcome the differences in the survival ability of host bacteria (Wang et al. 2012). Only few studies have been conducted to quantitatively assess the effects of ambient temperature anaerobic digestion on AR genes in cattle manure. However, it has been stated that temperature and retention time would be critical parameters in bacterial survival process (Sahlström 2003). This probably would explain the slight efficacy of summer digestion in reducing AR genes. Furthermore, as shown by Ma et al. (2011), gene transfer might have been hindered by increase in temperature because microbial processes during anaerobic digestion may result in extracellular DNA damage, through hydrolysis and biodegradation. It is important to highlight that $16 \mathrm{~S}$ rRNA levels were stable during the fermentation time. As such, the reduction in AR genes in both seasons is not referred to the overall decrease in total bacteria.
Further to support the above hypothesis, a correlation analysis was performed. The data show positive correlation on the interactions between relative abundance of each gene evaluated in different season. Thus, ambient temperature anaerobic digestion might have different implications for different AR genes in both conditions, and the specific nature of these relations needs to be better addressed in further studies (Nõlvak et al. 2013).

To access eventual interactions between detection of resistance genes in digester effluent samples and occurrence of medically important micro-organisms, potentially pathogenic bacteria were screened in the digester effluents by metagenomic analyses. Microbial identification through 16S rRNA genes showed persistence of these bacteria in final samples in both seasons. Slight increases in the relative abundance of pathogens (\% of total) were identified in the winter than in summer samples analysed, but no significant difference was found. This result might indicate the discrete influence of temperature on the change in the community bacteria. However, several factors including system operation time may affect the amount of certain species. For further discussion of this hypothesis, studies should be conducted with higher number of digesters. Yet, Massé et al. (2011) indicated that temperature could diversify the abundance of bacteria pathogens in animal manure anaerobic digestion.

Gram-positive, such as Clostridium and Bacillus, and Gram-negative, such as Acinetobacter and Stenotrophomonas, were the most identified bacteria in the final samples. It is recognized from other studies that these bacteria are ubiquitous and opportunistic pathogens. Similar results previously reported showed that lowering these pathogens load is a major concern for any subsequent use of anaerobic digester effluents as biofertilizers (Watcharasukarn et al. 2009; Eikmeyer et al. 2013). Add to that, these results show that only small proportions were identified as pathogens. However, it has to be considered that the evaluated reactors were continuously fed with cattle manure. Hence, the pathogenic and AR genes load would not be reduced to the undetectable amounts.

Using real-time quantitative PCR to quantify AR genes, we may not evidence or discuss on the microbial viability, and whether the detected genetic markers are actually functional. On the other hand, the methodological approach used may have several advantages because it is based on genotype, and allows discussion on the presence of different genetic markers which might be available for vertical or horizontal transfer in the environment (Diehl and LaPara 2010; Burch et al. 2013).

Considering the digestion at mesophilic range presented, the AR removal and prevalence of bacteria pathogens did not follow a simple or stabilization trend with ambient temperature variation (summer and winter). Considering 
the practice of spreading of effluents from digesters into land used for the agriculture production, the presence of AR genes or putative pathogenic micro-organisms may lead to sanitary and ecological risks (Resende et al. 2014).

The data presented in this study raise significant concerns and information highly applicable to support a safe technological handle of anaerobic digestion using cattle manure as substrate. Even with the narrow temperature range, AR gene copy numbers were reduced form initial load and the detection of medically important bacteria did not vary between summer and winter seasons. The functional viability and persistence in both bacteria and AR genes remains in the open environment still remains unclear. Further prospective and quantitative studies should address the extent of the antimicrobial resistance phenomena in effluents management with implications for human, animal and environmental health.

\section{Acknowledgements}

The authors are grateful to Kim Milferstedt, for support to the program database analysis. This study was supported by grants from EMBRAPA's virtual Laboratory abroad (Labex Program) in Europe, Brazilian National Council for Scientific and Technological Development (CNPq), Research Support Foundation of Minas Gerais (FAPEMIG). The authors gratefully acknowledge Embrapa Dairy Cattle, Institut National de la Recherche Agronomique (INRA) and Federal University of Juiz de Fora (UFJF). We also thank Coordination of Improvement of the Personnel of Higher Education (CAPES) by the scholarship (Process 11853-12-3).

\section{Conflict of interest}

No conflict of interest declared.

\section{References}

Abubaker, J., Risberg, K. and Pell, M. (2012) Biogas residues as fertilisers - Effects on wheat growth and soil microbial activities. Appl Energy 99, 126-134.

Alexander, T.W., Yanke, L.J., Topp, E., Olson, M.E., Read, R.R., Morck, D.W. and McAllister, T.A. (2008) Effect of subtherapeutic administration of antibiotics on the prevalence of antibiotic-resistant Escherichia coli bacteria in feedlot cattle. Appl Environ Microbiol 74, $4405-4416$.

Alexander, T.W., Yanke, J.L., Reuter, T., Topp, E., Read, R.R., Selinger, B.L. and McAllister, T.A. (2011) Longitudinal characterization of antimicrobial resistance genes in feces shed from cattle fed different subtherapeutic antibiotics. BMC Microbiol 11, 19.
American Public Health Association (APHA). (2005) Standard Methods for Examination of Water and Wastewater, 21th edn. Washington, D.C.: American Water Works Association.

Beneragama, N., Iwasaki, M., Lateef, S.A., Yamashiro, T., Ihara, I. and Umetsu, K. (2013) The survival of multidrugresistant bacteria in thermophilic and mesophilic anaerobic co-digestion of dairy manure and waste milk. Anim Sci J 84, 426-433.

Burch, T.R., Sadowsky, M.J. and Lapara, T.M. (2013) Aerobic digestion reduces the quantity of antibiotic resistance genes in residual municipal wastewater solids. Front Microbiol 4, 17.

Chen, J., Yu, Z., Michel, F.C., Wittum, T. and Morrison, M. (2007) Development and application of real-time PCR assays for quantification of erm genes conferring resistance to macrolides-lincosamides-streptogramin B in livestock manure and manure management systems. Appl Environ Microbiol 73, 4407-4416.

Diehl, D.L. and LaPara, T.M. (2010) Effect of temperature on the fate of genes encoding tetracycline resistance and the integrase of class 1 integrons within anaerobic and aerobic digesters treating municipal wastewater solids. Environ Sci Technol 44, 9128-9133.

Eikmeyer, F.G., Rademacher, A., Hanreich, A., Hennig, M., Jaenicke, S., Maus, I., Wibberg, D., Zakrzewski, M. et al. (2013) Detailed analysis of metagenome datasets obtained from biogas-producing microbial communities residing in biogas reactors does not indicate the presence of putative pathogenic microorganisms. Biotechnol Biofuels 6, 49.

Fonseca, G.P., Cruz, A.G., Faria, J.A.F., Silva, R., Moura, M.R.L. and Carvalho, L.M.J. (2009) Antibiotic residues in Brazilian UHT milk: a screening study. Food Sci Technol 29, 451-453.

Ghosh, S. and LaPara, T.M. (2007) The effects of subtherapeutic antibiotic use in farm animals on the proliferation and persistence of antibiotic resistance among soil bacteria. ISME J 1, 191-203.

Heuer, H., Schmitt, H. and Smalla, K. (2011) Antibiotic resistance gene spread due to manure application on agricultural fields. Curr Opin Microbiol 14, 236-243.

Holm-Nielsen, J.B., Al Seadi, T. and Oleskowicz-Popiel, P. (2009) The future of anaerobic digestion and biogas utilization. Bioresour Technol 100, 5478-5484.

Kemper, N. (2008) Veterinary antibiotics in the aquatic and terrestrial environment. Ecol Indic 8, 1-13.

Kunz, A., Steinmetz, R.L.R., Rammeb, M.A. and Coldebella, A. (2009) Effect of storage time on swine manure solid separation efficiency by screening. Bioresour Technol 100, 1815-1818.

Lachmayr, K.L., Kerkhof, L.J., Dirienzo, G., Cavanaugh, C.M. and Ford, T.E. (2009) Quantifying nonspecific TEM betalactamase (blaTEM) genes in a wastewater stream. Appl Environ Microbiol 75, 203-211.

Ma, Y., Wilson, C.A., Novak, J.T., Riffat, R., Aynur, S., Murthy, S. and Pruden, A. (2011) Effect of various sludge 
digestion conditions on sulfonamide, macrolide, and tetracycline resistance genes and class I integrons. Environ Sci Technol 45, 7855-7861.

Massé, D., Gilbert, Y. and Topp, E. (2011) Pathogen removal in farm-scale psychrophilic anaerobic digesters processing swine manure. Bioresour Technol 102, 641-646.

Munir, M. and Xagoraraki, I. (2011) Levels of antibiotic resistance genes in manure, biosolids, and fertilized soil. J Environ Qual 40, 248.

Negreanu, Y., Pasternak, Z., Jurkevitch, E. and Cytryn, E. (2012) Impact of treated wastewater irrigation on antibiotic resistance in agricultural soils. Environ Sci Technol 46, 4800-4808.

Nero, L.A., Mattos, M.R., Beloti, V., Barros, M.A.F. and Franco, B.D.G.M. (2007) Antimicrobial residues in raw milk from four Brazilian milk-producing regions. Food Sci Technol 27, 391-393.

Nõlvak, H., Truu, M., Tiirik, K., Oopkaup, K., Sildvee, T., Kaasik, A., Mander, U. and Truu, J. (2013) Dynamics of antibiotic resistance genes and their relationships with system treatment efficiency in a horizontal subsurface flow constructed wetland. Sci Total Environ 461-462, 636-644.

Pribul, B.R., Pereira, I.A., Soares, L.C., Coelho, S.M.O., Barberis, I.L., Pascual, L. and Souza, M.M.S. (2011) Bacterial resistance and bacteriocins action in Staphylococcus aureus isolated from bovine mastitis. Braz J Vet Res An Sci 63, 744-748.

Pruden, A., Larsson, D.G.J., Amézquita, A., Collignon, P., Brandt, K.K., Graham, D.W., Lazorchak, J.R., Suzuki, S. et al. (2013) Management options for reducing the release of antibiotics and antibiotic resistance genes to the environment. Environ Health Perspect 121, 878-885.

Pruesse, E., Quast, C., Knittel, K., Fuchs, B.M., Ludwig, W.G., Peplies, J. and Glockner, F.O. (2007) SILVA: a comprehensive online resource for quality checked and aligned ribosomal RNA Sequence data compatible with ARB. Nucleic Acids Res 35, 7188-7196.

Ramirez, M.S. and Tolmasky, M.E. (2010) Aminoglycoside modifying enzymes. Drug Resist Updat 13, 151-171.

Resende, J.A., Silva, V.L., Oliveira, T.L.R., Fortunato, S.O., Carneiro, J.C., Otenio, M.H. and Diniz, C.G. (2014) Prevalence and persistence of potentially pathogenic and antibiotic resistant bacteria during anaerobic digestion treatment of cattle manure. Bioresour Technol 153, 284-291.

Roberts, M.C. (2008) Update on macrolide-lincosamidestreptogramin, ketolide, and oxazolidinone resistance genes. FEMS Microbiol Lett 282, 147-159.

Sahlström, L. (2003) A review of survival of pathogenic bacteria in organic waste used in biogas plants. Bioresour Technol 87, 161-166.

Sahlström, L., Aspan, A., Bagge, E., Danielsson-Tham, M.L. and Albihn, A. (2004) Bacterial pathogen incidences in sludge from Swedish sewage treatment plants. Water Res 38, 1989-1994.

Salverda, M.L., De Visser, J.A. and Barlow, M. (2010) Natural evolution of TEM-1 b-lactamase: experimental reconstruction and clinical relevance. FEMS Microbiol Rev 34, 1015-1036.

Schloss, P.D., Westcott, S.L., Ryabin, T., Hall, J.R., Hartmann, M., Hollister, E.B., Lesniewski, R.A., Oakley, B.B. et al. (2009) Introducing MOTHUR: open-source, platformindependent, community-supported software for describing and comparing microbial communities. Appl Environ Microbiol 75, 7537-7541.

Shi, P., Jia, S., Zhang, X.X., Zhang, T., Cheng, S. and Li, A. (2013) Metagenomic insights into chlorination effects on microbial antibiotic resistance in drinking water. Water Res 47, 111-120.

Snell-Castro, R., Godon, J.J., Delgenès, J.P. and Dabert, P. (2005) Characterization of the microbial diversity in a pig manure storage pit using small subunit rDNA sequence analysis. FEMS Microbiol Ecol 52, 229-242.

Syrogiannopoulos, G.A., Grivea, I.N., Ednie, L.M., Bozdogan, B., Katopodis, G.D., Beratis, N.G., Davies, T.A. and Appelbaum, P.C. (2003) Antimicrobial susceptibility and macrolide resistance inducibility of Streptococcus pneumoniae carrying erm(A), erm(B), or mef(A). Antimicrob Agents Chemother 47, 2699-2702.

Venglovsky, J., Sasakova, N. and Placha, I. (2009) Pathogens and antibiotic residues in animal manures and hygienic and ecological risks related to subsequent land application. Bioresour Technol 100, 5386-5391.

Walsh, J.J., Rousk, J., Edwards-Jones, G., Jones, D.L. and Williams, A.P. (2012) Fungal and bacterial growth following the application of slurry and anaerobic digestate of livestock manure to temperate pasture soils. Biol Fertil Soils 48, 889-897.

Wang, Y. and Qian, P. (2009) Conservative fragments in bacterial 16S rRNA genes and primer design for $16 \mathrm{~S}$ ribosomal DNA amplicons in metagenomic studies. PloS one 4, 7401.

Wang, L., Oda, Y., Grewal, S., Morrison, M., Michel, F.C. and Yu, Z. (2012) Persistence of resistance to erythromycin and tetracycline in swine manure during simulated composting and lagoon treatments. Microb Ecol 63, 32-40.

Watcharasukarn, M., Kaparaju, P., Steyer, J.P., Krogfelt, K. and Angelidaki, I. (2009) Screening Escherichia coli, Enterococcus faecalis, and Clostridium perfringens as indicator organisms in evaluating pathogenreducing capacity in biogas plants. Microb Ecol 58, 221-230.

Yu, Y., Lee, C., Kim, J. and Hwang, S. (2005) Group-specific primer and probe sets to detect methanogenic communities using quantitative real-time polymerase chain reaction. Biotechnol Bioeng 89, 670-679. 